\title{
Liquidity Cost Determinants in the Saudi Market
}

\author{
Ahmed Alzahrani
}

\begin{abstract}
- this paper examines liquidity as measured by both price impact and bid-ask spread. Liquidity determinants of large trades "block trades" in the Saudi market are examined using 124 companies that comprise all listed firms in the market. We use high frequency intraday data for the period 2005-2008 to provide out of sample evidence related to liquidity and information asymmetry. Bid-ask spread as a measure of liquidity was decomposed, using the model of Huang and Stoll (1997) to infer the information asymmetry patterns in the market. We use quoted spread (QBAS), relative spread (RBAS) and effective spread (EBAS) as three proxies for liquidity in the market. We find a price impact asymmetry between buyer-initiated block trades and seller-initiated block trades. Seller of block trades in the Saudi market pay higher liquidity premium than buyers of block trades. Our results provide new evidence from an order-driven market that has low degree of institutional investors and higher concentration of ownership.
\end{abstract}

Index Terms-Liquidity, price impact, Bid-ask spread block trades, Saudi stock market, information asymmetry.

\section{INTRODUCTION}

The relationship between stock returns and liquidity is one that is heavily studied in the microstructure literature of financial markets. There exists a lot of research, both empirical and theoretical, on the liquidity. Liquidity has various measures among which are stock's trading frequency, price impact, bid/ask spread and the depth of the market for that stock. More commonly is the usage of price impact and Bid/ask spread as measures of liquidity. Prior research has made substantial contribution toward understanding the determinants and components of price impact and bid/ask spread as well as patterns of liquidity exist in the market.

We use high frequency intraday data for the period 20052008 to provide out of sample evidence related to liquidity and information asymmetry. Bid-ask spread as a measure of liquidity was decomposed, using the model of Huang and Stoll (1997) to infer the information asymmetry patterns in the market. We use quoted spread (QBAS), relative spread (RBAS) and effective spread (EBAS) as three proxies for liquidity in the market.

The paper is organized as following. Section II discusses relevant literature regarding block trading and liquidity. Section III and IV describe, respectively, the data and methodology used to implement our analysis. Finally, section $\mathrm{V}$ ends with results and conclusion.

Manuscript received May 12, 2011.

Ahmed Alzahrani is with the Assistant Professor of Finance.Institute of Public Administration. P. O Box. 205 Riyadh (email: Zahraniaa@ipa.edu.sa; Tel: +96655 718 2842)

\section{LITERATURE REVIEW}

Liquidity is one of the main issues in microstructure literature. The word liquidity is often used in loose and imprecise way because it can cover many aspects. However, a market is considered perfectly liquid if a participant can trade at the observed prices irrespective to the quantity, time and order type (buy or sell) desired. It is defined as the ability to buy or sell significant quantities of a security quickly, anonymously, and with little price impact.

Since the start of market microstructures studies, liquidity has been the focus of some researchers trying to understand the price formation process. Starting with Demsetz (1968) who concludes that trading volume and number of trades, volatility, firm size and prices are the main determinants of liquidity. Tinic (1972) finds a positive relation between trading activity and liquidity and a negative relation between trading activity and volatility. Subsequent papers usually use bid-ask spread and price impact as main proxies for transaction costs and liquidity. These papers study the topic in two different ways. First, in cross sectional analysis where they investigate whether higher bid-ask spreads and higher price impact would lead to higher returns in assets. In general, these papers find positive relationship between expected stock returns and alternative proxies for individual illiquidity levels such as bid-ask spreads, price impacts and probability of informed trading (e,g., Amihud and Mendelson,1986, Brennan and Subrahmanyan ,1996) .

Second group of papers study the time-series properties of aggregate liquidity measures and find existence of liquidity patterns and predictability in how liquidity might affect asset prices. Example of these papers include ( Chordia et al.,2001; Hasbrouck and Seppi ,2001; Amihud, 2002).

It is generally accepted that asset prices are closely affected by liquidity risk and liquidity patterns. Many research papers have focused on the liquidity effect on assets prices, the main finding is that liquidity is negatively related to stock returns. For example, Amihud and Mendelson(1986) suggest that average liquidity is priced in the market while Pastor and Stambaugh (2003) find that security return sensitivity to market liquidity is a risk factor that is priced in the market. Amihud (2002), Bekaert et al., (2007) provide evidence that liquidity commoved with returns and can predict future returns.

In any stock exchange, liquidity can impact the price at which securities are traded, therefore, it is crucial to measure and model liquidity for the assets and the market in general. Various measures have been used for liquidity, e.g. Grossman and Miller (1988) indicate that market liquidity can be measured by investigating the ability of executing trades under the current quotes price and time wise. More commonly cited is Kyle's (1985) practical definition of 
liquidity. Kyle identifies three components of market liquidity; the bid-ask spread "tightness", the depth of the market for a particular stock, and resiliency. Tightness is defined as the cost of turning around a position over a short period of time. Generally, the narrower or the smaller the spread the more liquid is the market. Depth of the stock or the market in general is the volume needed to move the prices by a given amount. The larger volume needed to move the prices the higher liquid is the market. Resiliency is the speed with which prices return to equilibrium or current level following a large trade. The price effect of a trade in a resilient market is small and short-lived. Depth and breadth of the market are concepts that are closely related to each other. A deep market is a one that you find incremental quantity ready to for trade above and below current price level.

Amihud and Mendelson (1986) suggest that liquidity can be measured by the cost of immediate execution in a view that bid and ask price is the sum of the buying premium and the selling concession. Recent work has introduced different metrics of liquidity, such as the illiquidity measure of Amihud (2002) where he shows that expected market illiquidity increases expected return because essentially illiquidity ratio serves as a proxy for the price impact of trade. He has proposed a liquidity cost in the markets using daily dollar volume and stock returns where illiquidity is measured as the average ratio of the daily absolute return to the dollar trading volume on that day as follow:

$$
I L L I Q_{i}(t)=\frac{1}{\operatorname{Days}_{i}(t)} \sum_{d=1}^{\text {Days }(t)_{i}} \frac{\left|r_{i}(t d)\right|}{V_{i}(t d)}
$$

where ri(td) is the return of the ith security on day $d$ in tth month, $\mathrm{Vi}(\mathrm{td})$ is the dollar volume of the ith security on day $\mathrm{d}$ in th month, and Days $\mathrm{i}(\mathrm{t})$ is the total number of trade days of the ith security in th month. The basic intuition of this ratio is that the higher ILLIQ indicate the less liquidity a stock is. Thus, a higher ILLIQ means that the price of a stock changes more in response to smaller volume

Persaud (2003) identifies a different but rather insightful fourth measure for liquidity which he calls diversity .He argues that lack of diversity can lead to liquidity black holes. Diversity refers to the differences in beliefs among traders in their market view. Persaud states "a liquidity black hole is where price falls do not bring out buyers, but generate even more sellers." Contrary to the normal belief that when prices go down an increasing number of buyers will exist, this is a condition where liquidity dries up and falling prices incline more seller. One important factor of this condition is the homogeneity of investors and how it could create the liquidity black holes. A stock market crash where panic selling motivates more selling is a clear example of liquidity black holes.

Market liquidity is considered an important factor that is closely related to market efficiency and stability. Liquidity is an important determinant of market behaviour. A liquid market has more capacity to accommodate order flow, hence promoting efficiency of the market. Chordia et al. (2005) consider the market's capacity to accommodate order imbalances as an indicator of market efficiency.1

Market systems differ in their role of who provides liquidity. In a quote-driven system, the dealer is responsible for creating liquidity in the market. He stands by ready to buy and sell shares at anytime. Quantity of shares (volume) demanded or supplied is determined by the traders not the dealer creating inventory balance risk for him. Hence the dealer is given exclusive rights as compensation by an exchange over a share; therefore the dealer can post different prices for purchases and sales. The dealer buys at the bid price $\mathrm{P}_{\mathrm{b}}$ and sells for higher ask price $\mathrm{P}_{\mathrm{a}}$ and the spread is the difference between the bid and ask prices $\mathrm{P}_{\mathrm{b}}-$ $\mathrm{P}_{\mathrm{a}}$, known as the bid-ask spread. The spread is the main source of profit for the dealer in return for providing the market liquidity. The dealer sets prices first then investors submit quantities.

In contrast, in the order-driven system, investors voluntarily provide the liquidity for the market through the limit orders and subsequently creating the spread in the order book. Prices and quantities are set by investors as the order-driven system operates without intermediary. ${ }^{2}$ All orders are entered into the order book and wait for execution which could follow call auction or continuous auction mechanism. Trade transactions and best price levels on both sides are visible to all traders in the market, and orders submitted but not executed yet can be amended or cancelled by a trader.

Trading rules and mechanisms varies in the way liquidity provision is handled. For example, some markets allow for "upstairs market" to facilitate the large trade transactions. Upstairs market is a network of dealers and brokers that facilitate negotiation of block trades between the buyers and sellers or dealers who syndicate among themselves to take the other side of the trade. This alternative trading mechanism is used for different reasons, one of which is the information problem naturally embedded in the large trades as they may signal information to other investors thus creating adverse selection problem. The block trader might be at price disadvantage when a large trade moves the price unfavourably if the order is submitted to the downstairs market.

\section{DATA}

We use high frequency data (one minute interval). It is a unique dataset in the way that it includes all listed companies (124 companies) in the SSM and the market Index, Tadawul All Share Index (TASI) at the intraday level. The dataset contains all transactions which are timestamped to the nearest minute and in some cases it aggregates all transactions occurred within the minute. Any inference about the data is applicable to the whole market as the dataset is free from any sample bias. It is highly comprehensive dataset as it almost covers four-year intraday dataset, from Jan 2005 to September 2008, with over 16,076,414 records of all transactions and bid-ask quotes. We define block trades in our study as any trade

1 Conditions where buy (sell) orders outnumber sell (buy) orders for a security in the market, which might halt trading for that security.

${ }^{2}$ A broker exists to facilitate the matching of buyers and sellers in an electronic order driven market. 
with over 10.000 shares, which is $4,221,870$ trades or $20.8 \%$ of all trades in our sample. larger trades (blocks) were only considered in this study as an attempt to reduce the noise in the data. Tables 1,2and 3 describe main indicators of the dataset and some descriptive information.

TABLE 1: SAUDI STOCK MARKET MAIN INDICATORS.

\begin{tabular}{|c|c|c|c|c|c|c|}
\hline$\underset{\nabla}{\ddot{\Xi}}$ & 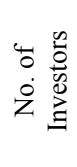 & 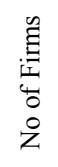 & 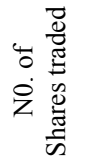 & 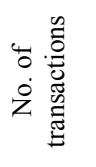 & 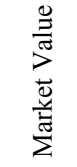 & 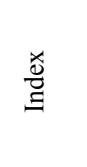 \\
\hline 2002 & N/A & 68 & 1,735 & 1,033 & 280 & 2,518 \\
\hline 2003 & N/A & 70 & 5,565 & 3,763 & 589 & 4,437 \\
\hline 2004 & 1,383 & 73 & 10,298 & 13,319 & 1,148 & 8,206 \\
\hline 2005 & 2,573 & 77 & 12,281 & 46,607 & 2,438 & 16.712 \\
\hline 2006 & 3,577 & 86 & 54,440 & 96,095 & 1,225 & 7,933 \\
\hline 2007 & 3,669 & 111 & 57.829 & 65,665 & 1,946 & 11,176 \\
\hline 2008 & 3,798 & 126 & 58,727 & 52,135 & 924 & 4,803 \\
\hline
\end{tabular}

Notes: Year of Trade, Number of investors present in the Saudi Stock Market(thousands), Number of Shares Traded(in millions), Number of Transactions(thousands), Market Value in Billions, and a Value Weighted Index for the Saudi Stock Market. The exchange rate is approximately (\$1=3.75 Saudi Riyal). Source: SAMA. Forty fourth Annual Reports.

TABLE 2: BLOCK TRADE DESCRIPTIVE INDICATORS.

$\begin{array}{lllll}\text { No of } & \text { Avg No } & \text { Avg } & \text { Avg } & \text { Avg } \\ \text { trades } & \text { of shares } & \text { Value } & \text { Quoted } & \text { Relative } \\ \text { '05-`08 } & & \begin{array}{l}\text { Per } \\ \text { trade }\end{array} & \text { Spread } & \text { Spread } \\ & & & & \end{array}$

\begin{tabular}{lccccc}
$\begin{array}{l}\text { All } \\
\text { trades }\end{array}$ & $16,076,414$ & 9 & 58 & 0.19 & 0.0030 \\
$\begin{array}{l}\text { Blocks } \\
26.2 \%\end{array}$ & $4,221,870$ & 29 & 1,880 & 0.3586 & 0.0063 \\
$\begin{array}{l}\text { Buy } \\
14.7 \%\end{array}$ & $2,366,099$ & 30 & 1,932 & 0.3607 & 0.0062 \\
$\begin{array}{l}\text { Sell } \\
11.5 \%\end{array}$ & $1,855,236$ & 28 & 1,827 & 0.3564 & 0.0064 \\
\hline
\end{tabular}

Note: This table reports the number of observations in the dataset with some descriptive statistics regarding the Averages of number of shares per trade(in thousands), average value(in thousands), average absolute spread and average relative spread for all the four categories of trades(All trades, Block trades, Buy Block trades and Sell Block trades).

$\begin{array}{cc}\text { TABLE 3: SUMMARY STATISTICS FOR BLOCK TRADES. } \\ \begin{array}{c}\text { No of trades } \\ \text { ' } 000\end{array} \text { Avg Value } & \text { Price Impact } \%\end{array}$

Panel A: Trade sign classification using Tick Rule.

\begin{tabular}{lccc} 
All Trades & \multicolumn{3}{c}{} \\
BlockTrade & 16,076 & 9,528 & 0.067 \\
$\mathbf{( 2 6 . 2 \% )}$ & 4,221 & 29,130 & 0.491 \\
Buy (14.7\%) & 2,366 & 30,046 & -0.388 \\
Sell(11.5\%) & 1,855 & 28,204 & \\
\hline \multicolumn{1}{c}{ Panel B: Trade sign classification using Midpoint Rule } \\
\hline Buy (10.6\%) & $1,714,072$ & 27,613 & 0.28777 \\
Sell (10.2\%) & $1,646,728$ & 23,472 & -0.1926 \\
\hline \hline
\end{tabular}

Notes: This table reports average of number of shares per trade, average value, average price impact and its variance. Panel A uses tick rule and Panel B used Midpoint test which shows less number of observations as we exclude unclassified trades that happen at the midpoint.

Panel A in Table 3 lists main characteristics of block trades using the tick rule. Block trades amount to $26.2 \%$ of all trades which is not as high when compared to more developed markets where institutional investors play an active role in the market. However, considering the lack of institutional investment in the SSM, block trades making up one quarter of all trading volume is very high percentage. Consistent with the literature, we define block trades to be of a volume of 10,000 or more.

\section{Methedology}

Since we sued two measures of liquidity in this study, price impact and bid-ask spread, we use two models to examine liquidity determinants in the market. Bid-ask spread is an indicator of the cost of trading and is a measure of market illiquidity. A central issue in the market microstructure research is the determinants of price impact and bid ask spread and their variation across securities or time. Prior research has made substantial contribution toward understanding the determinants and components of the bid/ask spread. A line of research that focuses empirically on which variables or trading activity measures can determine bid-ask spread and also capture variation in spread cross-sectionally include but not limited to Demsetz (1968), Tinic (1972), Stoll (1978), Jegadeesh and Subrahmanyam (1993) and Heflin and Shaw (2000). The results of these variables differ, but some of the main findings are that spread is a function of price level, volatility ,firms size, volume and the number of market makers. For example, Stoll (1978) and Jegadeesh and Subrahmanyam (1993) find that spread is correlated negatively with the price level, volume and the number of market makers, and positively associated with volatility. Heflin and Shaw (2000) find that spread is positively related to volatility and ownership concentration while negatively correlated to share prices, trade size and firm size.

Intuitively, higher volume reduces inventory cost for the market maker which would be reflected in the bid-ask spread. Moreover, the volatility variable seems always to have a positive relationship with the spread because of the uncertainty and adverse selection problems that are usually associated with higher volatile stock. All previously mentioned studies have the intention to capture which trading activities affect the spread, however, they were conducted in a market maker environment where the market maker is mainly responsible for setting the bid and ask quotes. The hypothesis that trading activity is indeed an important cause of liquidity is confirmed in limit older markets as well, including some of the recent theoretical work on limit order market (see, e.g., Foucault, et al., 2005; and Rosu, 2009)

The SSM is a purely order -driven market where the bid and ask prices are set by the demand and supply of traders in the market. We anticipate that trading activities will have similar effect that found in quote-driven market but some deviations are expected too. For example, the volume of the trade variable might reflect an adverse selection problem in an order-driven market rather than an inventory cost as in a specialist market, hence we expect some variables in the SSM to capture different aspects of the trading activities and will have different effects than those found in the literature. We focus on the determinants of bid-ask spread across different trading activities attributes and across time of the day to examine any variation or irregularities in the market using multivariate regression analysis. We attempt to examine cross-sectionally the relationship between bid/ask spread and trading activities similar to prior established work of Demsetz (1968), and Heflin and Shaw 
(2000). We also analyse intraday patterns in bid-ask spreads through dividing the trading day into three times intervals and use dummy variables for each interval. Contrary to the quote-driven market where market makers set the quotes, the interaction between market orders that demand liquidity and limit orders that supply liquidity determines the liquidity in an order driven market. As mentioned earlier in this thesis, there are various dimensions of liquidity that were discussed in the literature. For example, Harris (1990) defines four dimensions of liquidity: width, depth, immediacy and resiliency. We measure how trading activities affect the bid-ask spread which is the width measure of liquidity. However, other dimensions of liquidity are examined as well. To examine the relationship between market liquidity and trading activities we estimate various forms of the following OLS cross-section regression that is similar in principal to Heflin and Shaw (2000) Model where they measure the relationship between liquidity and ownership structure. Our model is similar also to Harris (1994) who uses the market value of shares outstanding as a proxy for adverse selection and also uses the standard deviation of returns as a direct measure of volatility.

For the determinants of liquidity, we include well documented variables from the literature; size of the trade, volatility of returns, size of the company, number of trades per day, sign of the trade (buy or sell), and dummy variables for time of the day.

$$
\begin{array}{r}
\text { Model( } 1) \text { Liquidity }=\alpha+\beta 1(\text { volume })+\beta 2 \text { (volatility })+ \\
\beta 3(\text { size })+\beta 4(\text { No of trades })+\beta 5(\text { trade sign })+\beta 6(\mathrm{t} 1)+ \\
\beta 7(t 2)+\beta 8(t 3)+\varepsilon
\end{array}
$$

where liquidity is either quoted spread (QBAS), relative spread (RBAS) or effective spread (EBAS). Volume is the natural logarithm of the number of shares per trade. Volatility is the standards deviation of returns computed from beginning of the day midpoint to the last trade prior to the current trade. Size is natural logarithm of the market value of common equity for each firm. Number of trades is the cumulative number of trades per day for each stock matched with the date of the trade. Trade sign is a dummy variable representing the direction of the trade using Lee and Ready (1991) "tick rule" classification technique, we assign value of 1 for buyer-initiated trades and value of 0 for seller-initiated trades. We include three dummy variables for the time of the day where the trading day is divided into three time intervals, first trading hour $\left(t_{1}\right)$, midday $\operatorname{trading}\left(t_{2}\right)$ and last trading hour $\left(t_{3}\right)$. All variables are computed from the intraday data of block trades, we include only trades with volume larger than 10,000 shares.

Easley and O'Hara (1987) indicate that informed traders prefer to trade a large amount at any given price, a finding that confirmed by many researchers. ${ }^{3}$ If this finding holds true, the adverse selection component of the spread should increase with trade size, subsequently, bid-ask spread should be higher. We expect trade size to have a positive signed coefficient with regard to bid-ask spread. Volatility is directly measured as the standard deviation of price returns. Volatility as a measure of risk is expected to widen the bid-ask spread, therefore we expect to have a positive

3 Look for example, (Kyle, 1985). coefficient with liquidity. The natural logarithm of the market value of shares outstanding serves as an inverse proxy for adverse selection costs. The larger the firm, the larger the government and other funds ownership which could indicated a greater degree of public information. Therefore, larger firms are believed to show less information asymmetry among investors and smaller adverse selection cost. We expect firm size to have a negative coefficient with the bid/ask spread.

The number of trades is a measure of trading frequency; the higher trading frequency the stock is the lower the spread and which induce lower transaction cost and higher liquidity in the market. The sign of coefficient for the number of the trades is expected to have negative relationship with regards to bid-ask spread. Trade sign is a dummy variable that takes the value of 1 if the trades are classified as buy and 0 for sell trades. We attempt to examine if a trade sign has any effect on liquidity in the market. Prior research has establish a price asymmetry between buy and sell block trades indicating that buy trades have permanent price impact on stocks while sell trades have somehow lower price impact that tends be transitory. In other words, sellers of block trades pay a liquidity premium. In fact the natural asymmetry between liquidity buyers and liquidity sellers lead to the asymmetry in price impact. If sale trades contain less information and are more motivated by liquidity then we would expect that purchase trades to have higher bid-ask spreads because of the higher probability of informed trading. Our results indicate that purchases have much greater effects on bid-ask spread than sales which can be explained by the fact that they are less likely to be driven by liquidity. Our result is in favour of the literature explanation of this asymmetry that is in purchases traders have to make actual investment decision whereas in sales the decision can be induced by a number of factors such as liquidity requirements or diversification needs.

Finally, the time dummy variables are included in the regression to examine any intraday patterns of liquidity. The microstructure literature has detected and reported various patterns of liquidity .One of the most famous pattern is the U-shaped bid-ask spread where the spread is at its highest at the opening and closing of the trading day (McInish and Wood, 1992). ${ }^{4}$ Similarly, Al-Suhaibani and Kryzanowski (2000) document the U-shaped pattern of liquidity in the SSM even though the market shows different structure and characteristics. Most of these patterns indicate high spread at the beginning of the trading session then declining during the day, a behaviour that can be related to uncertainty. The similarity in liquidity patterns in different market system, suggests that market maker alone, in a quote-driven market, cannot be accounted totally to the widening of the spread at the open and close of the trading session. Accordingly, we expect bid-ask spread to be at its highest at the opening and narrows as the trading hours continue and prices incorporate new information.

4 Some other well documented patterns include inverse U-shaped ,Jshaped, inverse J-shaped along with other patterns (e.g., McInish and Ness, 2002). 


\section{PRICE IMPACT}

The second measure we use to examine liquidity is price impact .In order to estimate the price impact of block trades, we classify the price effect of large transactions into three types which is a common practice in the literature ${ }^{5}$ Consistent with (Holthausen et al., 1990, and Gemmill, 1990, and Frino et al., 2007) we use five trades "minutes" benchmark to calculate price effects. ${ }^{6}$ The total price impact is calculated as the percentage return from five trades prior to the block trade to the block trade itself. The temporary price impact is calculated as the percentage return from the block trade to the fifth trade after the block trade. The permanent price impact represents the percentage return from five trades prior to the block trade to five trades after the block trade. Because quotes data are not directly available in the SSM, all prices used in the computations are transaction prices. The following equations represent the three types of price effect:

$$
\begin{gathered}
\text { Total Impact }=\frac{{\text { close }- \text { close } e_{-5}}_{\text {close }}}{\text { cl5 }^{-}}, \\
\text {Temorary Impact }=\frac{\text { close }_{+5}-\text { Close }}{\text { close }}, \\
\text { Permanent Impact }=\frac{\text { close }_{+5}-\text { close }_{-5}}{\text { close }_{-5}},
\end{gathered}
$$

We mainly follow Frino et al. (2007) model where the price impact of block trades is a function of a list of variables that thought to be the determinants of the price effect. The Following regression is estimated:

Model(2) Price Impac $=\alpha+\beta_{1}$ InSize $+\beta_{2}$ Volatility +

$\beta_{3}$ InTurnov $+\beta_{4}$ Market Return $+\beta_{5}$ momentum $+\beta_{6} B A S+\varepsilon$

\section{RESULTS}

$$
\begin{aligned}
\text { Liquidity }=\alpha+ & \beta_{1}(\text { volume })+\beta_{2}(\text { volatility })+\beta_{3}(\text { size }) \\
& +\beta_{4}(\text { No of trades })+\beta_{5}(\text { trade sign }) \\
& +\beta_{6}\left(t_{1}\right)+\beta_{7}\left(t_{2}\right)+\beta_{8}\left(t_{3}\right)+\varepsilon
\end{aligned}
$$

Volume is the natural logarithm of the number of shares per trade, volatility is the standards deviation of returns computed from beginning of the day midpoint to the last trade prior to the current trade, size is natural logarithm of the market value of common equity for each firm. Number of Trades is the cumulative number of trades per day for each stock matched with the date of the trade. Trade sign is a dummy variable taking value of 1 for buy trades and 0 for sell trades. Time of the day variation of liquidity patterns is examined through time dummies, $\mathrm{t} 1=$ first trading hour, $\mathrm{t} 2=$ midday trading hours, and $\mathrm{t} 3=$ last trading hour. Sample is split into two subsamples buy and sell block trades .Three measures have been used to proxy for liquidity that is quoted spread (QBAS), 2) relative Spread (RBAS) and 3) effective Spread (EBAS).spreads are calculated as the

5 Within the asymmetric information models, the permanent price impact of large trades is due to new information conveyed by the trade, while the temporary price impact is associated with liquidity shortages. For in depth analysis, refer to Glosten and Harris, 1988, Chan K. and Lakonishok, 1995, among many others).

6 Since we use intraday minute data, we use the terms "trades" and "minutes" interchangeably. following:

\begin{tabular}{|c|c|c|c|}
\hline VARIABLES & $\begin{array}{c}(1) \\
\text { QBAS }\end{array}$ & $\begin{array}{c}(2) \\
\text { RBAS }\end{array}$ & $\begin{array}{c}(3) \\
\text { EBAS }\end{array}$ \\
\hline Volur & $\begin{array}{l}\mathbf{0 . 0 6 8 2} * * * \\
(0.000222)\end{array}$ & $\begin{array}{c}\mathbf{0 . 0 0 1 5 5}^{* * *} \\
(3.28 \mathrm{e}-06)\end{array}$ & $\begin{array}{l}\mathbf{0 . 0 3 8 5}^{* * *} \\
(0.000199)\end{array}$ \\
\hline Volatility & $\begin{array}{c}\mathbf{0 . 3 2 1} * * * \\
(0.000250)\end{array}$ & $\begin{array}{c}\mathbf{0 . 0 0 1 2 4} * * * \\
(3.68 \mathrm{e}-06)\end{array}$ & $\begin{array}{c}\mathbf{0 . 2 1 9} * * * \\
(0.000223)\end{array}$ \\
\hline Size & $\begin{array}{c}-\mathbf{0 . 0 0 5 0 1} * * * \\
(0.000116)\end{array}$ & $\begin{array}{c}-0.000357^{* * *} \\
(1.72 \mathrm{e}-06)\end{array}$ & $\begin{array}{c}\mathbf{0 . 0 0 1 1 8} * * * \\
(0.000104)\end{array}$ \\
\hline No of Trades & $\begin{array}{c}-\mathbf{0 . 0 0 1 2 1} * * * * \\
(4.66 \mathrm{e}-06)\end{array}$ & $\begin{array}{c}-2.81 \mathrm{e}-06 \% * * \\
(6.88 \mathrm{e}-08)\end{array}$ & $\begin{array}{c}-\mathbf{0 . 0 0 1 1 5} * * * \\
(4.17 \mathrm{e}-06)\end{array}$ \\
\hline Trade sign & $\begin{array}{l}\mathbf{0 . 0 2 6 9} * * * \\
(0.000350)\end{array}$ & $\begin{array}{c}\mathbf{0 . 0 0 0 2 5 1} * * * * \\
(5.16 \mathrm{e}-06)\end{array}$ & $\begin{array}{l}\mathbf{0 . 0 1 4 8}^{* * *} \\
(0.000313)\end{array}$ \\
\hline TimeDummy1 & $\begin{array}{r}10.0202 * * * \\
(0.000645)\end{array}$ & $\begin{array}{c}\mathbf{0 . 0 0 0 4 6 2} * * * * \\
(9.52 \mathrm{e}-06)\end{array}$ & $\begin{array}{l}\mathbf{0 . 0 1 5 3} * * * \\
(0.000577)\end{array}$ \\
\hline TimeDummy2 & $\begin{array}{r}-\mathbf{- 0 . 0 3 2 5} \% * * ; \\
(0.000489)\end{array}$ & $\begin{array}{c}-\mathbf{0 . 0 0 0 4 7 8} \times * * * \\
(7.22 \mathrm{e}-06)\end{array}$ & $\begin{array}{c}\mathbf{- 0 . 0 3 4 1 * * * *} \\
(0.000438)\end{array}$ \\
\hline Constant & $\begin{array}{l}-\mathbf{- 0 . 2 7 7 * * *} \\
(0.00333)\end{array}$ & $\begin{array}{c}-\mathbf{0 . 0 0 2 8 2} \% * * \\
(4.92 \mathrm{e}-05)\end{array}$ & $\begin{array}{c}-\mathbf{0 . 2 2 1} * * * \\
(0.00298)\end{array}$ \\
\hline & 4221 & 4221872 & 4221872 \\
\hline R-squared & 0.291 & 0.085 & 0.192 \\
\hline
\end{tabular}

1) $\mathrm{QBAS}=$ ask price $_{\mathrm{t}}-$ bid price $_{\mathrm{t}}$,

2) $\operatorname{RBAS}=\frac{\left(\text { ask price }_{t}-\text { bid price }_{t}\right)}{\text { mid price }_{t}}$, and

3) $\quad$ EBAS $=2\left(\right.$ trade price $_{t}-$ mid price $\left._{t}\right)$.

Standard errors are reported in parentheses. $* * * \mathrm{p}<0.01, * * \mathrm{p}<0.05$, * $\mathrm{p}<0.1$

Notes: this table presents Cross-sectional OLS regression coefficients of the liquidity determinants in the SSM.

The quoted spread and effective spread report higher Rsquared at 27 and 22 percent, respectively. The relative spread report a lower R-squared at 8 percent only. Someone has to be careful when including the relative spread as a measure of liquidity. Bollen et al (2004) when reviewing Tinic and West (1974) work on the bid-ask determinants, states "For the relative spread regression to be correctly specified, all of the explanatory variables must be deflated by share price". All explanatory variables report significant coefficients at the $1 \%$ level for all forms of the models. Volume show positive relationship with the spreads indicating that informed traders tend to transact large volume, confirming to Easley and O'Hara (1987) model of informed trading. Volatility has significant positive effect, in fact its coefficients are the highest among all variables at 0.32 and 0.22 for the quoted and effective spread. Volatility augments spread in the SSM, a relationship that is very well documents in the literature. Size of the company has a negative relationship with the quoted bid-ask spread as expected with coefficient that is $(-0.005)$. The larger the firm the more well known and lower the possibility of adverse selection cost that is reflected in the spread. Our firm size relationship coincides with Heflin and Shaw (2000) who report a firm size coefficient of (0.008). Smaller firms in the SSM tend to be the target of both informed and speculative trading due to smaller number of shares and higher ability to control price movement of stocks regardless of fundamental values, therefore, smaller firms' stocks tend to show higher volatility and adverse selection costs.

However, the effective spread shows a positive 
coefficient with the size of the company, the larger the firm the higher the effective transaction cost .Effective spread shows how a round-trip trade price was placed relative to the midpoint price(price improvement) and the tendency for larger orders to move the price (price impact) . Naturally, larger orders are associated with larger company size, the positive relationship between firm size and effective spread maybe due to the price impact of larger orders. Moreover, larger companies in the SSM exhibit higher stock prices, hence higher effective spread is also expected.

Number of trades which is a measure of the trading frequency appears to have a negative relationship with all types of spreads, confirming to prior research ( Kim and Ogden,1996; Heflin and and Shaw ,2000; Giouvris and Philppatos, 2008) who also found significant negative relationship between number of trades per day and the components of the bid-ask spread. Number of trades can be explained as a way of reducing information asymmetry in the market. If a stock is relatively traded frequently, traders relate frequency of the trade as a high liquid stock, therefore the spread tightens between the bid and the ask prices. The trade sign dummy variable, 1 for buy trades and 0 for sell trades, indicates that on average buyer-initiated trades increase the spread more than seller-intuited trades with coefficients of $2.7 \%$ and $1.5 \%$ for the quoted and effective spread, respectively. A relationship that is supported by the numerous literature findings of price impact asymmetry between buy and sell block trades. Finally, the time dummies suggest that liquidity cost is at its highest at the beginning of the trading day then decreases throughout the trading day before it bounces again toward the end of the trading day forming an inverse J-shaped bid-ask spread pattern similar to McInish and Wood (1992). The time dummies coefficients for all types of spreads quoted, relative and effective report similar patterns of a positive coefficients for time dummy1 at 0.2, 0.0004, and 0.015 ,respectively, then followed be negative signs reported in the same order for timedummy 2 at (-0.03), ($0.0005)$ and(-0.034). Our time of the day results are consistent with Frino et al.(2007) who find liquidity cost or price impact is the largest for of block trades executed at the first hour. Moreover, our intraday spread pattern is somehow similar to Al-Suhaibani and Kryzanowski (2000) who find that spreads are at their highest at the open and narrow over the trading day in the SSM. An obvious explanation for this pattern is that adverse selection is highest at the beginning of the day and as trading continues the information asymmetry decrease or incorporated in the prices. Graph (1) shows the average bid- ask spread pattern throughout the trading hours.

\section{PRICE IMPACT}

Table 5 shows the regression results of the determinants of the price impact of block trades. The Price impact, dependent variable, is one of three types; permanent, total and temporary price effects.

Size is the natural logarithm of the number of shares per trade, Volatility is the standard deviation of trade to trade prices on the trading day before the block trade is taking place, Turnover is the natural logarithm of the total stock turnover on the trading day prior to the block trade, BAS is the bid-ask spread (relative to the midpoint between bid and ask) at the time of the block trade. Market Return is TASI returns on the day of block trade. Finally Lagged Return is the five days cumulative returns of the stock preceding the block trade

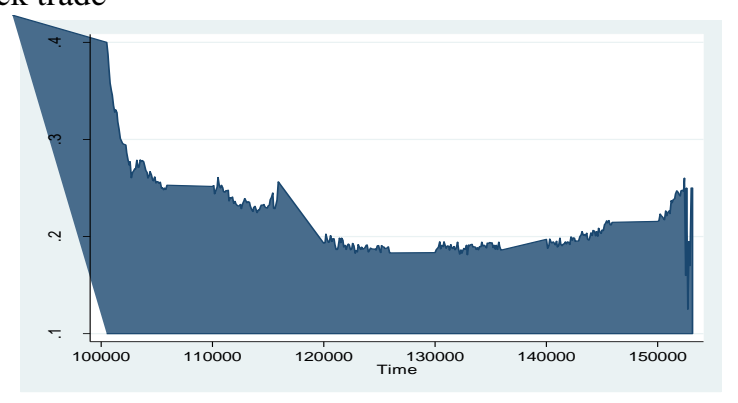

Figure 1 : Intraday Variation Pattern of the Spread

Notes: The graph shows the intraday pattern for the effective bid/ask spread in the SSM averaged across all observation by the minute as the following:

EBAS $_{\mathrm{t}}=\frac{1}{\mathrm{~N}} \sum_{\mathrm{t}=1}^{270} 2\left(\right.$ trade $_{\text {price }} \mathrm{t}-$ mid price $\left._{\mathrm{t}}\right)$. Spread is at its highest at the beginning of the trading hours then decreases throughout the trading day before it bounces again toward the end of the trading day forming an inverse J-shaped pattern similar to McInish and Wood (1992) and closely confirming Al-Suhaibani and Kryzanowski (2000) for the Saudi market.

TABLE 5: LIQUIDITY (PRICE IMPACT) DETERMINANTS IN THE SSM

\begin{tabular}{|c|c|c|c|}
\hline & Permanent & Total & Temporary \\
\hline & effects & effects & effe \\
\hline \multicolumn{4}{|c|}{$\overline{\text { Panel A: Price Effect }}$} \\
\hline Mean Return & $-0.0108 * * *$ & $-0.00965 * * *$ & -0.00 \\
\hline \multicolumn{4}{|l|}{$\begin{array}{l}\text { Panel B: } \\
\text { Coefficients }\end{array}$} \\
\hline Ln(size) & $\begin{array}{c}\mathbf{0 . 0 0 1 0 6}^{* * * *} \\
(7.32 \mathrm{e}-06)\end{array}$ & $\begin{array}{c}\mathbf{0 . 0 0 0 9 5 7} * * * * \\
(5.87 \mathrm{e}-06)\end{array}$ & $\begin{array}{c}9.89 \mathrm{e}-05^{* * * *} \\
(5.36 \mathrm{e}-06)\end{array}$ \\
\hline Volatility & $\begin{array}{c}\mathbf{0 . 0 0 0 3 6 8}^{* * * *} \\
(8.93 \mathrm{e}-06)\end{array}$ & $\begin{array}{c}\mathbf{0 . 0 0 0 4 3 9} * * * * \\
(7.16 \mathrm{e}-06)\end{array}$ & $\begin{array}{c}-6.14 e-05 * * * \\
(6.53 e-06)\end{array}$ \\
\hline Ln(turnover) & $\begin{array}{c}-\mathbf{0 . 0 0 0 1 4 7} * * * * \\
(3.36 \mathrm{e}-06)\end{array}$ & $\begin{array}{c}-\mathbf{0 . 0 0 0 1 2 1} * * * \\
(2.69 \mathrm{e}-06)\end{array}$ & $\begin{array}{c}-2.93 e-05 * * * * \\
(2.46 e-06)\end{array}$ \\
\hline Mktreturn & $\begin{array}{l}\mathbf{0 . 0 6 6 3}^{* * * *} \\
(0.000288)\end{array}$ & $\begin{array}{l}\mathbf{0 . 0 3 7 0} * * * \\
(0.000231)\end{array}$ & $\begin{array}{l}\mathbf{0 . 0 2 9 3} * * * \\
(0.000211)\end{array}$ \\
\hline Momentum & $\begin{array}{c}\mathbf{- 0 . 0 0 0 2 6 4} * * * * \\
(3.15 \mathrm{e}-05)\end{array}$ & $\begin{array}{c}-\mathbf{0 . 0 0 0 3 4 6} \\
(2.53 \mathrm{e}-05)\end{array}$ & $\begin{array}{c}\mathbf{7 . 1 3 e - 0 5 * * *} \\
(2.31 \mathrm{e}-05)\end{array}$ \\
\hline BAS(relative) & $\begin{array}{c}-\mathbf{0 . 0 3 9 2} * * * \\
(0.00110)\end{array}$ & $\begin{array}{l}\mathbf{- 0 . 0 6 0 4} * * * \\
(0.000880)\end{array}$ & $\begin{array}{l}\mathbf{0 . 0 2 7 6}^{* * * *} \\
(0.000803)\end{array}$ \\
\hline$\overline{\text { R-squared }}$ & 0.018 & 0.013 & 0.005 \\
\hline
\end{tabular}

Standard errors in parentheses, $* * * \mathrm{p}<0.001, * * \mathrm{p}<0.05, * \mathrm{p}<0.1$

Panel A reports the mean price effect of the independent variables using three types of price impact permanent, total and temporary. All price impacts are calculated using transaction prices. On Average, the temporary effect is only $-0.11 \%$ whereas the total effect is $-0.965 \%$ for all block trades. The temporary impact as a measure for immediate demand effect shows that immediacy is not highly priced in the SSM which indicate a higher depth for the market .Hence, liquidity traders have very low level of price impacts on stocks, which is considered as non-informational price impact. 


\section{TRADE SIGN EFFECT}

We report liquidity behaviour with regard to sign of the trade as the literature suggests that liquidity shows different behaviour according to the sign of the trade.

Block purchases transactions in Panel A have a mean return for the permanent price impact at $(-1.43 \%)$ and ($0.37 \%$ ) for the transitory effect. We mentioned earlier that the SSM seems to be more sensitive to informed trading, which has permanent effect on the price impact, than to liquidity trades which have transitory effect on stock prices. With regards to sell transactions in panel $\mathrm{B}$, the mean permanent price impact is $(-0.026 \%)$ while the temporary price impact is $0.23 \%$.

The regression results of the estimated coefficients for the explanatory variables are all significantly different from zero at the $1 \%$ level. Size (trade volume) coefficients are significantly positive for the block purchases and significantly negative for the block sales. The size of the trade coefficients show, as the literature suggest, direct positive effect on the price impact, the larger the volume the greater the effect. Volume has both transitory and permanent effects on prices which mean volume convey information to the market and that other traders would change the perceived market value of a stock according to volume traded. The price impact is an increasing a function of the trade size.

Volatility as measured by the standard deviation of returns represents the market risk faced by the traders, therefore higher volatility has greater price impact on a stock and is expected to have a positive relationship with the price effect. Volatility shows positive coefficient for the buy block trades and negative for sell trades which confirm the greater price impact that is attributed to higher risk and dispersion of beliefs among traders. The volatility coefficients are consistent with prior research (e.g., Chan and Lakonishok, 1997; Chiyachantana et al., 2004; Frino et al., 2007)

Turnover has negative relationship to price impact for the buy blocks, indicating that increased liquidity in the market reduces the price impact of the block trade. Our results confirm prior market research that turnover as a measure of liquidity should have negative relationship with the price impact. The negative relationship between liquidity and price impact can in part be linked to a more general relationship between stock returns and liquidity. For example, Hu (1997) argues that turnover is a useful measure of liquidity and a negative relation between stock returns and turnover exists. Brennan and Subrahmanyam (1996) also find a negative relation between expected returns and liquidity. Conversely, the block sales has negative turnover coefficient, indicating that increased liquidity induce greater price impact. Large block sales combined with highly active traded stocks might convey negative information because they reflect a likely action of informed traders and induce more selling which increases the price effect of these large trades.

The market return has positive coefficients for both block purchases and sales, a higher market return indicate greater price impact for the block purchases and a lower price impact for block sales. Our market return coefficients are consistent with Frino et al. (2007) where they have positive coefficient for both subsamples, buy and sell, and the market coefficient is higher for block sales than purchases.

The momentum in price returns has negative (positive) coefficient with the price impact for the block purchases (sales), indicating a lower price impact following a price trend. Our result lends support to Saar (2001) who finds that recent large price run-up of a stock leads to a lower price impact for both block purchases and sales. A stock that has shown an increased momentum trend in its performance is expected to have a lower price impact for block trades, the price-run up effect. This relationship between the price impact of trades and the history of price performance (momentum) is similar to the one documented in Chiyachantana et al. (2004). They report that the institutional purchases of stocks with several days of price run-up induce smaller permanent price change.

TABLE 6 : PRICE IMPACt ESTIMATES AND TRADE Sign (BUy BLOCK TRADES)

\begin{tabular}{ccll}
\hline \hline & $\begin{array}{c}\text { Permanent } \\
\text { effects }\end{array}$ & $\begin{array}{l}\text { Total } \\
\text { effects }\end{array}$ & $\begin{array}{l}\text { Temporary } \\
\text { effects }\end{array}$ \\
\hline \hline Ln(size) & $\mathbf{0 . 0 0 1 5 2} * * *$ & $\mathbf{0 . 0 0 1 1 4} * * *$ & $\mathbf{0 . 0 0 0 3 8 2} * * *$ \\
& $(8.79 \mathrm{e}-06)$ & $(6.54 \mathrm{e}-06)$ & $(6.69 \mathrm{e}-06)$ \\
Volatility & $\mathbf{0 . 0 0 1 5 7} * * *$ & $\mathbf{0 . 0 0 1 4 1} * * *$ & $\mathbf{0 . 0 0 0 1 6 9} * * *$ \\
& $(1.16 \mathrm{e}-05)$ & $(8.62 \mathrm{e}-06)$ & $(8.82 \mathrm{e}-06)$ \\
Ln(turnover) & $\mathbf{- 0 . 0 0 0 3 1 1} * * \mathbf{0 . 0 0 0 3 6 6} * * * \mathbf{4 . 9 1 e - 0 5} * * *$ \\
& $(1.04 \mathrm{e}-05)$ & $(7.70 \mathrm{e}-06)$ & $(7.88 \mathrm{e}-06)$ \\
Mktreturn & $\mathbf{0 . 0 3 6 1} * * *$ & $\mathbf{0 . 0 1 0 6} * * *$ & $\mathbf{0 . 0 2 5 2} * * *$ \\
& $(0.000364)$ & $(0.000271)$ & $(0.000277)$ \\
Momentum & $\mathbf{- 0 . 0 0 0 5 1 4} * *-\mathbf{0 . 0 0 1 1 4} * * *$ & $\mathbf{0 . 0 0 0 6 0 6} * * *$ \\
& $(4.13 \mathrm{e}-05)$ & $(3.07 \mathrm{e}-05)$ & $(3.15 \mathrm{e}-05)$ \\
BAS(relative) $) \mathbf{0 . 2 4 7} * * *$ & $\mathbf{0 . 3 6 1} * * *$ & $\mathbf{- 0 . 1 0 9} * * *$ \\
& $(0.00139)$ & $(0.00103)$ & $(0.00106)$ \\
Constant & $\mathbf{- 0 . 0 1 4 3} * * *$ & $\mathbf{- 0 . 0 1 0 4} * * *$ & $\mathbf{- 0 . 0 0 3 7 8} * * *$ \\
& $(8.96 \mathrm{e}-05)$ & $(6.66 \mathrm{e}-05)$ & $(6.82 \mathrm{e}-05)$ \\
Observations 2366099 & $\mathbf{2 3 6 6 0 9 9}$ & $\mathbf{2 3 6 6 0 9 9}$ \\
& 0.045 & 0.089 & 0.009 \\
\hline \hline
\end{tabular}

TABLE 7 : PRICE IMPACT ESTIMATES AND TRADE SIGN (SELL BLOCK TRADES)

\begin{tabular}{lccc}
\hline \hline & $\begin{array}{c}\text { Permanent } \\
\text { effects }\end{array}$ & $\begin{array}{l}\text { Total } \\
\text { effects }\end{array}$ & $\begin{array}{l}\text { Temporary } \\
\text { effects }\end{array}$ \\
\hline \hline Ln(size) & $\mathbf{- 0 . 0 0 0 9} * * *$ & $\mathbf{0 . 0 0 0 1 4 5} * * *$ & $\mathbf{- 0 . 0 0 0 2 4 6} * * *$ \\
& $(1.10 \mathrm{e}-05)$ & $(8.10 \mathrm{e}-06)$ & $(8.63 \mathrm{e}-06)$ \\
Volatility & $\mathbf{- 0 . 0 0 0 5 6 8} * * *$ & $\mathbf{- 0 . 0 0 0 1 7 2} * * *$ & $\mathbf{- 0 . 0 0 0 3 8 9 * * *}$ \\
& $(1.28 \mathrm{e}-05)$ & $(9.48 \mathrm{e}-06)$ & $(1.01 \mathrm{e}-05)$ \\
Ln(turnover) & $\mathbf{- 0 . 0 0 0 3 6 2} * * *$ & $\mathbf{- 7 . 5 4 e - 0 5} * * *$ & $\mathbf{- 0 . 0 0 0 2 9 4} * * *$ \\
& $(1.12 \mathrm{e}-05)$ & $(8.29 \mathrm{e}-06)$ & $(8.83 \mathrm{e}-06)$ \\
Mktreturn & $\mathbf{0 . 0 7 5 0} * * *$ & $\mathbf{0 . 0 3 6 8} * * *$ & $\mathbf{0 . 0 3 8 5} * * *$ \\
& $(0.000406)$ & $(0.000301)$ & $(0.000320)$ \\
Momentum & $\mathbf{0 . 0 0 0 5 3} * * *$ & $\mathbf{0 . 0 0 0 4 8 3} * * *$ & $\mathbf{- 0 . 0 0 0 4 5 9} * * *$ \\
& $(4.27 \mathrm{e}-05)$ & $(3.16 \mathrm{e}-05)$ & $(3.37 \mathrm{e}-05)$ \\
BAS(relative) & $\mathbf{- 0 . 3 2 7} * * *$ & $\mathbf{- 0 . 5 0 7} * * *$ & $\mathbf{0 . 1 8 8} * * *$ \\
& $(0.00154)$ & $(0.00114)$ & $(0.00122)$ \\
Constant & $\mathbf{- 0 . 0 0 0 2 0 6} *$ & $\mathbf{- 0 . 0 0 2 5 1} * * *$ & $\mathbf{0 . 0 0 2 3 7} * * *$ \\
& $(0.000111)$ & $(8.23 \mathrm{e}-05)$ & $(8.77 \mathrm{e}-05)$ \\
Observations & $\mathbf{1 8 5 5 2 3 6}$ & $\mathbf{1 8 5 5 2 3 6}$ & $\mathbf{1 8 5 5 2 3 6}$ \\
R-Squared & $\mathbf{0 . 0 5 4}$ & $\mathbf{0 . 1 1 7}$ & $\mathbf{0 . 0 2 0}$ \\
\hline \hline
\end{tabular}

Notes: The table presents estimated parameters separately for the buy and sells subsamples. We use tick test for trade classification. Buyer initiated trades (2,366,099 observations) are reported in panel A and seller initiated trades $(1,855,236$ observations) are reported in panel B. Standard errors in parentheses. $* * * \mathrm{p}<0.01, * * \mathrm{p}<0.05, * \mathrm{p}<0.1$

Moreover, the momentum variable for the sell transaction shows a positive relationship with regard to the temporary price effect (negatively signed coefficient) and a negative relationship with the permanent price impact (positively signed coefficient). The reverse in the sign of the 
momentum indicate the price reversal of the block sales. Finally, we find that BAS has positively significant coefficient for buyer- initiated block trades and negatively significant coefficient for seller- initiated block trades. When spread is wider the price impact is greater for both buy and sell block trades. Our BAS coefficients are consistent with Gemmil(1996) and Frino et al.(2007).

Our results thus provide some evidence that permanent price impact for block purchases increases following larger trades, less liquidity, higher volatility and market returns. Permanent price impact is decreased when the stock is actively traded and when it has just established a weekly trend in its price momentum. In contrasts, the regression results suggest that permanent price impact for block sales increases when associated with larger trading volume, higher volatility and high turnover. The coefficients for market returns and momentum for the block sales suggest that price impact is decreased when there are higher market returns or when a stock has recently experienced a recent trend in its returns performance. It is worthy to mention that total price effect reports the highest adjusted-R among other price impacts in both buy and sell block trades. Total price impact is calculated from five minutes before the execution of the block price and it suggests the SSM is very quick into incorporating the block trade information into prices. Once a block order, either sell or buy, is displayed on screen, the market react immediately with greater price impact followed by a price reversal once the block trade has been executed.

\section{CONCLUSION}

Our result provide out of sample evidence from the Saudi Stock Market using high frequency data on liquidity determinants using two measures Price impact and Bid-Ask spread. Both measures confirm higher liquidity that is associated with higher trading activity. Our price impact measure exhibits a price impact asymmetry (liquidity premium) between stock sales and purchases. Moreover, our finding suggests that resiliency is high in the SSM as most of the price impact fade away 5 minutes post the trade.

\section{REFERENCES}

[1] AL-SUHAIBANI, M. and KRYZANOWSKI, L., 2000. The Information Content of Orders on the Saudi Stock Market. Journal of Financial Research, 23(2), 145-156.

[2] AMIHUD, Y., 2002. Illiquidity and stock returns: cross-section and time-series effects. Journal of Financial Markets, 5(1), 31-56.

[3] AMIHUD, Y. and MENDELSON, H., 1986. Asset pricing and the bid-ask spread. Journal of Financial Economics, 17(2), 223-249.

[4] BOLLEN, N.P.B., SMITH, T. and WHALEY, R.E., 2004. Modeling the bid/ask spread: measuring the inventory-holding premium. Journal of Financial Economics, 72(1), 97-141

[5] BRENNAN, M.J. and SUBRAHMANYAM, A., 1996. Market microstructure and asset pricing: On the compensation for illiquidity in stock returns. Journal of Financial Economics, 41(3), 441-464.

[6] BEKAERT, G., HARVEY, C.R. and LUNDBLAD, C., 2007. Liquidity and expected returns: Lessons from emerging markets. Review of Financial Studies, 20(6), 1783.

[7] CHAN, L.K.C. and LAKONISHOK, J., 1995. The behavior of stock prices around institutional trades. JOURNAL OF FINANCE, 50, $1147-1147$.

[8] CHAN, L.K.C. and LAKONISHOK, J., 1997. Institutional equity trading costs: NYSE versus Nasdaq. Journal of Finance, 52, 713-736.
[9] CHIYACHANTANA, C.N., JAIN, P.K., JIANG, C. and WOOD, R.A., 2004. International evidence on institutional trading behavior and price impact. Journal of Finance, 59, 869-898.

[10] CHORDIA, T., ROLL, R. and SUBRAHMANYAM, A., 2005. Evidence on the speed of convergence to market efficiency. Journal of Financial Economics, 76(2), 271-292

[11] CHORDIA, T., ROLL, R. and SUBRAHMANYAM, A., 2001. Market liquidity and trading activity. Journal of Finance, 56, 501530.

[12] DEMSETZ, H., 1968. The Cost of Transacting. The Quarterly Journal of Economics, 82(1), 33-53.

[13] EASLEY, D. and O'HARA, M., 1987. Price, trade size, and information in securities markets. Journal of Financial Economics, 19, 69-90.

[14] FOUCAULT, T., KADAN, O. and KANDEL, E., 2005. Limit order book as a market for liquidity. Review of Financial Studies, 18(4), 1171-1217.

[15] FRINO, A., JARNECIC, E. and LEPONE, A., 2007. The determinants of the price impact of block trades: further evidence. Abacus, 43(1), 94-106.

[16] GEMMILL, G., 1996. Transparency and liquidity: A study of block trades on the London Stock Exchange under different publication rules. Journal of Finance, 51, 1765-1790.

[17] GIOUVRIS, E. and PHILIPPATOS, G., 2008. Determinants of the Components of the Bid-Ask Spreads on the London Stock Exchange: The Case of Changes in Trading Regimes. Journal of Money, Investment and Banking, (1), 49-61.

[18] GLOSTEN, L.R. and HARRIS, L., 1988. Estimating the components of the bid-ask spread. Journal of Financial Economics, 21(1), 123142.

[19] GROSSMAN, S.J. and MILLER, M.H., 1988. Liquidity and market structure. Journal of Finance, 43, 617-633.

[20] HARRIS, L.E., 1994. Minimum Price Variations, Discrete Bid--Ask Spreads, and Quotation Sizes. Review of Financial Studies, 7(1), 149178.

[21] HARRIS, L.E., 1990. Liquidity, trading rules, and electronic trading systems. (New York, N.Y.): New York University Salomon Center.

HASBROUCK, J. and SEPPI, D.J., 2001. Common factors in prices, order flows, and liquidity. Journal of Financial Economics, 59(3), 383-411.

[22] HEFLIN, F. and SHAW, K.W., 2000. Blockholder ownership and market liquidity. Journal of Financial and Quantitative Analysis, 35, 621-633.

[23] HOLTHAuSEN, R., LEFTWICH, R. and MAYERS, D., 1990. Large Block Transactions, the Speed of Response, and Temporary and Permanent Stock Price Effects. Journal of Financial Economics, 26, 71-95

[24] HUANG, R.D. and STOLL, H.R., 1997. The components of the bidask spread: a general approach. Review of Financial Studies, 10(4), 995-1034.

[25] HU, S., 1997. Trading turnover and expected stock returns: The trading frequency hypothesis and evidence from the Tokyo stock exchange. working paper edn. Available at SSRN: http://ssrn.com/abstract=15133 .

[26] JEGADEESH, N. and SUBRAHMANYAM, A., 1993. Liquidity effects of the introduction of the S\&P 500 index futures contract on the underlying stocks. The Journal of Business, 66(2), 171-187.

[27] KIM, S.H. and OGDEN, J.P., 1996. Determinants of the components of bid-ask spreads on stocks. European Financial Management, 2(1), 127-145.

[28] KYLE, A.S., 1985. Continuous auctions and insider trading. Econometrica: Journal of the Econometric Society, 53(6), 1315-1335.

[29] LEE, C. and READY, M., 1991. Inferring trade direction from intraday data. Journal of Finance, 46(2), 733-746

[30] MCINISH, T.H. and VAN NESS, B.F., 2002. An intraday examination of the components of the bid-ask spread. The Financial Review, 37(4), 507-524. MCINISH, T.H. and WOOD, R.A., 1992. An analysis of intraday patterns in bid/ask spreads for NYSE stocks. Journal of Finance, 47, 753-764.

[31] PERSAUD, A., 2003. Liquidity black holes: understanding, quantifying and managing financial liquidity risk. Risk Books

[32] PASTOR, L. and STAMBAUGH, R.F., 2003. Liquidity risk and expected stock returns. Journal of Political economy, 111(3), 642-685.

[33] ROSU, I., 2009. A dynamic model of the limit order book. Review of Financial Studies, (April), 1-41.

[34] STOLL, H.R., 1978. The pricing of security dealer services: An empirical study of NASDAQ stocks. Journal of Finance, 33(4), 1153-1172. 
[35] TINIC, S.M., 1972. The economics of liquidity services. The Quarterly Journal of Economics, 86, 79-93.

[36] TINIC, S.M. and WEST, R.R., 1974. Marketability of common stocks in Canada and the USA: A comparison of agent versus dealer dominated markets. Journal of Finance, 29, 729-746.
Ahmed Alzahrani is an Associate Professor of Finance at direcotr of Private Sector Programes at I Institute of Public Administration Riyadh,Saudi Arabia. He earned his PhD in finance at University of Brunel ,London in 2010 .His research Interest covers finance and business areas such as Capital Market, corporate performance , market microstructur. 